\title{
Hemoparasitoses em cães: análise de dados laboratoriais
}

\author{
Hemoparasitosis in dogs: laboratory data analysis
}

\author{
Jéssica Colombo Breda ${ }^{{ }^{*}}$, Adriana Dalpicolli Rodrigues ${ }^{2,3}$, Patrícia Kelly Wilmsen Dalla Santa Spada ${ }^{1}$, Tânia Torriani ${ }^{4}$ \\ ${ }^{1}$ Faculdade de Biomedicina, Centro Universitário da Serra Gaúcha (FSG), Caxias do Sul, RS, Brasil \\ ${ }^{2}$ Centro Universitário UniFtec, Caxias do Sul, RS, Brasil \\ ${ }^{3}$ Laboratório Alfa Ltda, Caxias do Sul, RS, Brasil \\ ${ }^{4}$ BichoLab, Bento Gonçalves, RS, Brasil
}

\section{Resumo}

O objetivo desse trabalho foi avaliar a ocorrência de hemoparasitos em cães, consultando os laudos de análises sanguíneas de um laboratório de análises clínicas veterinárias do município de Bento Gonçalves, RS. Para tanto, foram avaliados 413 laudos emitidos de janeiro a junho do ano de 2013, cuja técnica utilizada foi a hematoscopia. Dos laudos avaliados com hemoparasitos, 45/53 (84,9\%) apontaram eritrócitos parasitados por Babesia sp./Rangelia vitalli, 5/53 (9,4\%) para leucócitos parasitados e níveis plaquetários diminuídos devido à Ehrlichia sp., e $3 / 53$ (5,7\%) parasitados simultaneamente por Babesia sp./R. vitalli e Ehrlichia sp. As amostras também foram caracterizadas pela evidência de anemia, sendo que $120 / 413$ cães $(29,1 \%)$ apresentavam quadro anêmico, 40 desses hemoparasitados; 293/413 $(70,9 \%)$ não apresentaram anemia e 13/293 desses eram hemoparasitados. Na série vermelha, estavam laudados quadros de anisocitose, policromatofilia e/ou presença de eritroblastos para 129/413 (31,2\%) cães, sendo 43/129 hemoparasitados; já 284/413 (68,8\%) cães não apresentaram alterações da série vermelha, sendo 10/284 hemoparasitados. Para a série branca, $301 / 413$ cães $(72,9 \%)$ foram indicados com quadros de leucocitose, leucopenia, linfocitose e/ou neutrofilia, sendo que 50/301 desses (24,9\%) eram hemoparasitados; $112 / 413(27,1 \%)$ não apresentaram alterações da série branca, onde 3/112 eram hemoparasitados. Quanto às alterações plaquetárias, a trombocitopenia foi detectada em 131/413 (31,7\%) cães, sendo 37/131 desses hemoparasitados; $282 / 413$ (68,3\%) não apresentaram alterações, dos quais 16/282 eram hemoparasitados. Mediante esses achados, pode-se constatar que as alterações hematológicas geralmente estão associadas à presença de hemoparasitos e os resultados servem para alertar sobre a importância do manejo adequado do local de vivência dos cães, certificando-se da ausência de carrapatos.

Palavras-chave: Hemotoscopia. Cães. Babesiose. Rangeliose. Erliquiose. 


\section{Abstract}

The aim of this study was to evaluate the occurrence of haemoparasites in dogs analyzing blood tests of a Laboratory of Veterinary Clinical Analysis in Bento Gonçalves, RS. In order to do the research, we evaluated 413 reports issued from January to June 2013, and the technique used was hematoscopy. From the analyzed reports with haemoparasites, 45/53 (84.9\%) indicated erythrocytes parasitized by Babesia sp./Rangelia vitalli; $5 / 53$ (9.4\%) for parasitized leukocytes and decreased platelet levels due Ehrlichia sp.; and 3/53 (5.7\%) parasitized simultaneously by Babesia sp./R. vitalli and Ehrlichia sp. Samples were characterized by the evidence of anemia: from 120/413 dogs (29.1\%) with anemia, 40/120 were haemoparasites; 293/413 dogs (70.9\%) didn't show anemia, but 13/293 of them were haemoparasites. In the red series, there were reports of anisocytosis, polychromatophilia and/ or presence of erythroblasts for 129/413 (31.2\%) dogs, with 43/129 of them haemoparasites; on the other hand, $284 / 413$ (68.8\%) dogs did not present alterations of the red series, being 10/284 haemoparasites. In the white series, 301/413 dogs (72.9\%) had leukocytosis, leucopenia, lymphocytosis and/or neutrophilia, of which 50/301 (24.9\%) were haemoparasites; $112 / 413$ (27.1\%) did not present changes in the white series, whereas $3 / 112$ were haemoparasites. Regarding platelet alterations, thrombocytopenia was detected in 131/413 (31.7\%) dogs, where 37/131 were haemoparasites; 282/413 (68.3\%) did not present alterations, out of which 16/282 were haemoparasites. According to this study, it is possible to state that hematological alterations are usually associated to the presence of haemoparasites, and the results alert to the importance of a proper management of the dogs' living space, ensuring the absence of ticks.

Keywords: Haematoscopy. Dogs. Babesiosis. Rangeliosis. Erlichiosis.

\section{Introdução}

Os hematozoários e bactérias hemotrópicas são agentes que parasitam células sanguíneas, acarretando complicações no organismo animal como anemia hemolítica, trombocitopenia, insuficiência renal e, até mesmo, óbito. Carrapatos contaminados são responsáveis pela transmissão dos hemoparasitos, sendo esses os vetores responsáveis, e as suas espécies se diferenciam acerca de cada agente infeccioso (Andrade et al., 2014).

A babesiose foi descrita pela primeira vez no Brasil em 1918, e a erliquiose, em 1973. Ambos os agentes infecciosos são transmitidos pelo carrapato Rhipicephalus sanguineus (Costa et al., 2015). A babesiose é causada por um hemoparasita, Babesia spp., que infecta eritrócitos; a erliquiose, por uma bactéria Gram-negativa, a Rickettsia, que infecta os leucócitos. A erliquiose altera a produção de trombócitos por mecanismos que podem incluir a produção anormal de plaquetas, geralmente acompanhada de outra citopenia como anemia e/ou neutropenia, e diminuição da produção de trombócitos (Ferreira Neto et al., 1981).

A rangeliose, transmitida pelo carrapato Amblyomma aureolatum (Rivero et al., 2017) e descrita no Brasil em 1908, apresenta semelhanças com a Babesia spp. devido aos sinais clínicos, alterações e morfologia microscópica das células sanguíneas. Podem ser diferenciadas pela espécie do carrapato vetor e pela técnica de reação em cadeia da polimerase (PCR), que permite a identificação do gênero e da espécie em questão (Silva et al., 2012). Essas hemoparasitoses, em geral, podem ser classificadas por nomenclaturas populares como "doença do carrapato", "orelhas sangrentas" ou "peste do sangue", compatibilizando conforme os sinais clínicos e alterações do animal (Soares, 2014; Makino et al., 2016).

A presença de ectoparasitos, como carrapatos, e sinais clínicos característicos em cães podem inferir uma possível hemoparasitose, com a necessidade de um diagnóstico que pode ser direto, pela hematoscopia, buscando estruturas celulares compatíveis com o agente suspeito (Sousa et al., 2010). Se utilizada apenas a técnica de hematoscopia para o diagnóstico de babesiose e ehrliquiose, utilizam-se as nomenclaturas Babesia sp. e Ehrlichia sp., visto que possuem diferentes espécies não identificáveis pela visualização direta. A rangeliose pode ser indicada como Rangelia vitalli no laudo, já que se conhece uma única espécie (Rotondano et al., 2015).

Por meio da observação das inclusões intracelulares é possível identificar o agente etiológico, 
mas, em contrapartida, a identificação definitiva da espécie por esta técnica não é possível. Desta forma, é necessário o diagnóstico de confirmação em nível molecular, definindo-se o agente hemoparasitário. A técnica de PCR, que inclui protocolos dos genes dsb e 18S, possui alto grau de especificidade e sensibilidade ao resultado, sendo possível detectar e amplificar as sequências de genes de cada hemoparasito, assim identificando e diferenciando a espécie (Aguiar, 2007; Guimarães, 2009). 0 diagnóstico por PCR é uma escolha dos tutores de cães que, devido ao custo do exame, podem optar por não realizar a confirmação, o que acaba implicando em um resultado inespecífico (Duarte, 2011).

Conforme sua fase de infecção, os cães hemoparasitados apresentam sinais clínicos de grande valia para o diagnóstico. As formas nas quais os agentes etiológicos se apresentam no organismo animal, interligadas às alterações do hemograma e correlacionadas às disfunções hepáticas (encefalopatia hepática ou neoplasias) e renais (insuficiência), também contribuem para o diagnóstico correto (Carvalho et al., 2008).

Os agentes etiológicos das hemoparasitoses podem se apresentar nas fases subclínicas, hiperagudas, agudas, crônicas ou atípicas, porém as de maior relevância clínica são as fases agudas e crônicas (Sousa, 2010). A babesiose e a rangeliose possuem morfologia da estrutura parasitária e mecanismo de infecção bem semelhantes. A babesiose, no entanto, apresenta-se como estruturas piriformes, arredondadas ou elípticas e geralmente aos pares, podendo apresentar quatro, oito ou mais deles dentro de um único eritrócito; a rangeliose geralmente aparece em formas piriformes nas células endoteliais dos vasos sanguíneos (Lemos et al., 2012). Dessa forma, devido à multiplicação da Babesia dentro dos eritrócitos e do ataque às células endoteliais pela Rangelia, ocorre a hemólise e, em sequência, a liberação de hemoglobina na circulação e consequentes bilirrubinemia e hemoglobinúria. Os quadros graves apresentam sangramentos intensos, principalmente na região das orelhas e focinho, bem como hemorragias (Spolidorio et al., 2013).

Quanto aos achados laboratoriais para erliquiose, são observados inicialmente como corpúsculos e corpos elementares que se unem e formam a mórula na erliquiose monocítica, vista em leucócitos mononucleados (monócitos e linfócitos), que são destruídos, comprometendo o sistema imunológico do animal (Manoel, 2010).

Devido à preocupação que causam as hemoparasitoses, o objetivo desse estudo foi analisar os resultados de hematoscopias de amostras de cães quanto à pesquisa de hemoparasitos e parâmetros hematológicos que incluíram alterações como anisocitose, policromatofilia, presença de eritroblastos, leucocitose, neutrofilias e trombocitopenia.

\section{Materiais e métodos}

Foi realizado um estudo transversal e retrospectivo, referente ao período de janeiro a junho de 2013. Foram analisados 413 laudos do banco de dados de um laboratório de análises clínicas veterinárias do município de Bento Gonçalves, RS, acerca de cães que foram investigados quanto aos sinais clínicos e à suspeita de hemoparasitoses pelo médico veterinário, que por sua vez solicitou investigação de hemoparasitos.

0 sangue foi recebido no laboratório, devidamente acondicionado, seguindo imediatamente para a realização do hemograma e análise hematoscópica. 0 hemograma foi realizado em equipamento automatizado da marca Sysmex $^{\circledR}$, modelo pocH-100iV. Os esfregaços sanguíneos foram corados pelo método panótico rápido e posteriormente visualizados à microscopia óptica, com objetiva de imersão em aumento de $1.000 \mathrm{x}$, à procura de corpúsculos elementares (iniciais ou mórulas) em leucócitos e plaquetas.

A consulta dos laudos permitiu avaliar os perfis hematológicos dos cães, identificando as possíveis alterações nas séries vermelha e branca e perfil plaquetário, além do diagnóstico de hemoparasitose.

\section{Análise estatística}

As variáveis analisadas se referiam à presença de hemoparasitos, indicação de anemia, alterações das séries vermelha e branca (leucocitose, leucopenia, neutrofilia, eosinofilia) e de plaquetas. A análise estatística foi realizada com tabelas de contingência $2 \times 2$, utilizando-se os testes de Qui-quadrado e 
exato de Fisher para possível associação entre as variáveis, considerando-se a diferença estatística para $\mathrm{p} \leq 0,05$ no programa SPSS 20.0 para Windows.

\section{Resultados}

Por meio da análise dos laudos, pode-se observar que $12,8 \%$ dos cães (53/413) foram diagnosticados como hemoparasitados pela técnica de hematoscopia, sendo 50,9\% (27/53) fêmeas e $49,1 \%$ (26/53) machos. Dos laudos dos cães hemoparasitados, 84,9\% (45/53) apresentaram eritrócitos infectados por Babesia sp./Rangelia vitalli, 9,4\% (5/53) apresentaram leucócitos infectados e alterações plaquetárias por Ehrlichia sp., e 5,7\% (3/53) apresentaram infecções tanto em eritrócitos quanto em leucócitos e plaquetas. Diante disso, a Babesia sp./Rangelia vitalli foi significativamente mais frequente na amostra avaliada (teste de Q-quadrado; $\mathrm{p} \leq 0,001$ ).

A avaliação dos parâmetros hematológicos dos 413 laudos avaliados está apresentada na Tabela 1. Quanto à evidência ou não de anemia (sinal clínico de possível hemoparasitose), pode-se observar que $29,1 \%$ dos cães $(120 / 413)$ estavam anêmicos, sendo que 33,3\% (40/120) hemoparasitados; $70,9 \%$ (293/413) não apresentaram anemia, porém 4,4\% (13/293) eram hemoparasitados.

Um total de $31,2 \%$ dos cães (129/413) apresentava alterações da série vermelha, sendo 33,3\% (43/129) hemoparasitados; 68,7\% (284/413) não apresentaram alterações da série vermelha, porém 3,5\% (10/284) estavam hemoparasitados.

Em relação à série branca, 72,9\% (301/413) dos cães apresentaram alterações, sendo 16,6\% (50/301) hemoparasitados; 27,1\% (112/413) não apresentaram alterações da série branca, no entanto, 2,7\% (3/112) estavam hemoparasitados. A avaliação estatística dos dados avaliados nos laudos indicou que as alterações hematológicas se relacionam significativamente com a presença de hemoparasitos ( $\mathrm{p} \leq 0,001)$.

Quanto às alterações plaquetárias, 31,7\% (131/413) dos cães apresentaram-na, sendo 28,2\% (37/131) hemoparasitados; 68,3\% (282/413) não apresentaram-na, apesar de 5,7\% (16/282) estarem hemoparasitados. Os tipos de alterações dos parâmetros hematológicos nos cães diagnosticados com hemoparasitos estão descritos na Tabela 2 .

Tabela 1 - Avaliação dos parâmetros hematológicos e presença de hemoparasitos, confirmados por hematoscopia, em laudos de 413 cães, emitidos por um laboratório de análises clínicas veterinárias de Bento Gonçalves, RS

\begin{tabular}{lccc}
\hline \multicolumn{1}{c}{ Parâmetros } & Perfil dos cães $\mathbf{n}(\%)^{*}$ & Animais hemoparasitados $\mathbf{n}(\%)^{* *}$ & Valor de $\mathbf{p}^{* * *}$ \\
\hline Anemia & $120(29,1)$ & $40(75,5)$ & $0,001 \ddagger$ \\
Sim & $293(70,9)$ & $13(24,5)$ & \\
Não & & & $0,001 \ddagger$ \\
Alteração da série vermelha & $43(81,1)$ & \\
Sim & $129(31,2)$ & $10(18,9)$ & $0,001 \S$ \\
Não & $284(68,8)$ & & \\
Alteração da série branca & & $50(94,3)$ & \\
Sim & $301(72,9)$ & $3(5,7)$ & $0,001 \ddagger$ \\
Não & $112(27,1)$ & & \\
Alteração plaquetária & & $37(69,8)$ & \\
Sim & $131(31,7)$ & $16(30,2)$ & \\
Não & $282(68,3)$ & &
\end{tabular}

Nota: ${ }^{*}$ Porcentagens calculadas sobre 0 total analisado (413). ${ }^{* *}$ Porcentagens calculadas sobre os hemoparasitados (53). ${ }^{* * *}$ Valores significativos para $p \leqslant 0,05 . \ddagger$ Teste de Qui-quadrado; § Teste exato de Fisher. 
Tabela 2 - Especificações das alterações hematológicas relatadas em laudos de 53 cães hemoparasitados (n), emitidos por um laboratório de análises clínicas veterinárias de Bento Gonçalves, RS

\begin{tabular}{|c|c|c|c|}
\hline Parâmetro avaliado & Descrição & $\mathbf{n}$ & $\%$ \\
\hline \multirow[t]{7}{*}{ Série vermelha $(n=43)$} & Anisocitose & 8 & $18,6 \%$ \\
\hline & Policromatofilia & 11 & $25,6 \%$ \\
\hline & Anisocitose e policromatofilia & 8 & $18,6 \%$ \\
\hline & Anisocitose, policromatofilia e presença de eritroblastos & 11 & $25,6 \%$ \\
\hline & Anisocitose e presença de eritroblastos & 2 & $4,6 \%$ \\
\hline & Policromatofilia e presença de eritroblastos & 2 & $4,6 \%$ \\
\hline & Presença de eritroblastos & 1 & $2,3 \%$ \\
\hline \multirow[t]{8}{*}{ Série branca $(n=50)$} & Desvio à esquerda & 4 & $12,5 \%$ \\
\hline & Leucocitose neutrofílica & 5 & $10,0 \%$ \\
\hline & Leucocitose neutrofílica e desvio à esquerda & 11 & $22,0 \%$ \\
\hline & Leucocitose neutrofílica, desvio à esquerda e presença de linfócitos atípicos & 3 & $6,0 \%$ \\
\hline & Leucopenia com neutrofilia e desvio à esquerda & 2 & $4,0 \%$ \\
\hline & Neutrofilia relativa & 4 & $8,0 \%$ \\
\hline & Neutrofilia absoluta com desvio à esquerda & 3 & $6,0 \%$ \\
\hline & Outras alterações & 18 & $36,0 \%$ \\
\hline Plaquetas $(n=37)$ & Trombocitopenia & 37 & $100,0 \%$ \\
\hline
\end{tabular}

\section{Discussão}

Os 53 casos positivos para hemoparasitoses avaliados foram relevantes principalmente por não haver tropismo dos vetores, por conta do clima onde os cães viviam, visto que locais de clima tropical são preferidos pelos hemoparasitos (Gottlieb et al., 2016). A transmissão de hemoparasitos ocasionada por carrapatos, como a babesiose e a erliquiose, possuem como vetor responsável o $R$. sanguineus, encontrado geralmente na área urbana, onde os cães vivem mais dentro de casa ou em pátios, sendo estes locais mais secos (Gottlieb et al., 2016). 0 carrapato A. aureolatum é encontrado mais frequentemente em zonas rurais, possuindo maior afinidade por regiões com mata e locais úmidos (Soares, 2014). Assim, o local onde vivem/permanecem e o relato da presença ou não de carrapatos são informações de grande relevância para o diagnóstico de hemoparisitoses. Segundo informações do responsável técnico pelo laboratório de análises clínicas, isso é questionado aos tutores, porém essas informações não ficam registradas no laudo.

Em um estudo que avaliou 58 cães com sinais clínicos para hemoparasitoses, através do exame de imunoflorescência indireta foi verificada sorologia positiva com um resultado de $74,9 \%$ para Babesia spp. (55,5\% dos casos positivos) e $R$. vitalli $(19,4 \%$ dos casos positivos), no qual o exame foi realizado por PCR convencional (Gottlieb et al., 2016). Esse valor é inferior ao encontrado em nosso estudo, onde verificou-se $84,9 \%$ de infecção por Babesia sp. e R. vitalli. Já o valor de infecções por Ehrlichia canis (Gottlieb et al., 2016) foi de $25 \%$, enquanto no presente estudo foi de 9,4\%. Rotondano et al. (2015), ao fazerem a avaliação hematológica de 100 cães através de PCR e sequenciamento de DNA, obtiveram 69,2\% para Ehrlichia canis e 30,8\% para Babesia spp. associada com Babesia vogeli, enquanto no presente estudo os valores foram de $9,4 \%$ e $85,9 \%$, respectivamente. 
Fighera etal. (2010) avaliaram 35 cães com sinais de apatia, anorexia e icterícia, diagnosticados com R. vitalli, sendo que $26(74,3 \%)$ deles apresentaram anemia, percentual semelhante aos achados deste estudo (75,5\%). Conforme Mendonça et al. (2005), as hemoparasitoses em geral provocam anemia, principalmente em infecções por erliquiose, sendo bastante frequentes, também, em infecções por babesiose e rangeliose. Os autores avaliaram 109 cães hemoparasitados, dos quais 85 (78\%) apresentaram anemia, valores semelhantes aos encontrados neste estudo, onde $84(98,8 \%)$ cães estavam com anemia regenerativa.

No estudo de Fighera etal. (2010), 26 cães (74,3\%) apresentaram alterações hematológicas da série vermelha, nas quais havia presença de acentuada anisocitose e policromatofilia, fato esse observado em cerca de $98 \%$ dos casos avaliados nos laudos do presente estudo. A destruição das hemácias pode ocorrer pelo sistema monocítico-macrofágico e/ ou lise destas células por ação do complemento e uma reação de hipersensibilidade do tipo II, ou devido à supressão da eritropoiese, confirmando que os achados de anisocitose e policromatofilia são subsídios científicos para a afirmação de anemia regenerativa (Mendonça, 2005).

Mendonça et al. (2005) relataram alterações hematológicas na série branca, bem como nos níveis plaquetários, sendo que $55(50,5 \%)$ cães apresentaram desvio à esquerda, diferente deste estudo, que registrou 23 casos (71,9\%). Os autores realataram 27 casos $(24,8 \%)$ de leucopenia e $24(22 \%)$ de linfopenia, enquanto neste estudo foram registrados $2(6,2 \%)$ cães com leucopenia e nenhum com linfopenia. Foi relatado ainda que dos 109 cães estudados, 95 (87,15\%) apresentavam trombocitopenia, enquanto neste estudo 37 $(28,2 \%)$ apresentaram a mesma alteração. A grande variação e discordância entre os estudos de diferentes pesquisadores se deve a fatores inerentes à patogenicidade das cepas, ao curso de infecção, à resposta individual dos animais e à presença de agentes infecciosos concomitantemente (Mendoça et al., 2005) .

A presença de hemoparasitoses, anemias, alterações das séries vermelha e branca, bem como perfil plaquetário foram dados evidenciados neste estudo, não sendo possível a diferenciação das espécies entre Babesia sp. e Rangelia vitalli $(84,9 \%$ do total de hemoparasitados) devido à limitação de técnicas do laboratório. Sabe-se que a babesiose e a rangeliose possuem o mesmo tropismo pelo tipo celular, sinais clínicos semelhantes, estruturas iguais, bem como fases agudas e crônicas. 0 fato é que a rangeliose, além de ser intraeritrocitária, pode apresentar suas formas piriformes circulantes e em células endoteliais dos vasos sanguíneos, assim seus quadros dehemorragiasetornam mais graves dosque os da babesiose, e ambas, pelos seus mecanismos de hemólise dos eritrócitos, geram processos anêmicos no organismo do animal (Fhigera, 2010). Dessa forma, a diferenciação das espécies se torna possível a partir de um diagnóstico secundário, tendo como técnica de escolha o exame de PCR (Gottlieb et al., 2016). Apesar da indicação do médico veterinário, o laboratório onde esses cães foram avaliados quanto à presença de hemoparasitos não realizou o exame por opção e decisão dos tutores desses animais. Uma vez que não haja a solicitação do PCR, o laboratório descreve em seus laudos as duas hemoparasitoses em concomitância (Babesia sp./Rangelia vitalli), não havendo interferência quanto ao tratamento, já que os tratamentos se assemelham e são eficazes para ambas as hemoparasitoses (Costa, 2014).

A infecção por Ehrlichia sp. totalizou 9,4\% dos cães laudados nesse laboratório no período de janeiro a junho de 2013. A erliquiose está relacionada com o sistema imunológico do animal devido à capacidade de destruição dos leucócitos, podendo gerar respostas como leucocitose ou leucopenia (Sousa, 2010), observadas em cerca de 35\% e 4\% dos casos avaliados nesse estudo, respectivamente.

\section{Conclusão}

Os 413 laudos avaliados nesse estudo, datados do primeiro semestre do ano de 2013, trazem uma importante contribuição, visto que 12,8\% dos laudos apresentavam diagnóstico positivo de hemoparasitos. Apesar da não diferenciação de diagnóstico entre babesiose e rangeliose, indicados em $84,9 \%$ das análises positivas, os resultados servem para alertar tutores sobre a importância do manejo adequado do local de vivência dos cães, certificando-se da ausência de carrapatos. Outro 
alerta é a indicação/convencimento dos tutores para a confirmação dos agentes causadores através do exame PCR, para um diagnóstico preciso, mesmo que o tratamento medicamentoso se assemelhe para infecções por Babesia spp./Rangelia vitalli.

\section{Referências}

Aguiar DM, Saito TB, Hagiwara MK, Machado RZ, Labruna MB. Diagnóstico sorológico de erliquiose canina com antígeno brasileiro de Ehrlichia canis. Cienc Rural. 2007;37(3):796-802.

Andrade GB, Barreto WTG, Santos LL, Ribeiro LRR, Macedo GC, Sousa KCM, et al. Pathology of dogs in Campo Grande, MS, Brazil naturally coinfected with Leishmania infantum and Ehrlichia canis. Rev Bras Parasitol Vet. 2014;23(4):509-15.

Carvalho FS, Wenceslau AA, Carlos RSA, Albuquerque GR. Epidemiological and molecular study of Ehrlichia canis in dogs in Bahia, Brazil. Genet Mol Res. 2008;7(3):657-62.

Costa AP, Costa FB, Labruna MB, Silveira I, Moraes-Filho J, Soares JF, et al. A serological and molecular survey of Babesia vogeli, Ehrlichia canis and Rickettsia spp. among dogs in the state of Maranhão, northeastern Brazil. Rev Bras Parasitol Vet. 2015;24(1):28-35.

Costa MP. Avaliação hematológica de sangue e medula óssea e bioquímica sérica de cães infectados naturalmente por hemoparasitos [dissertação]. Belo Horizonte: Universidade Federal de Minas Gerais; 2014. p. 21-5.

Duarte SC, Parente JA, Pereira M, Soares CM, Linhares GFC. Phylogenetic characterization of Babesia canis vogeli in dogs in the state of Goiás, Brazil. Rev Bras Parasitol Vet. 2011;20(4):274-80.

Ferreira Neto JM, Viana ES, Magalhães LM. Patologia clínica veterinária. Belo Horizonte: Rabelo; 1981.

Fighera RA, Souza TM, Kommers GG, Irigoyen LF, Barros CSL. Pathogenesis, clinical, hematological, and pathological aspects of Rangelia vitalii infection in 35 dogs (1985-2009). Pesq Vet Bras. 2010;30(11):974-87.
Gottlieb J, André MR, Soares JF, Gonçalves LR, Oliveira MT, Costa MM, et al. Rangelia vitalli, Babesia spp. and Ehrliquia spp. in dogs in Passo Fundo, state of Rio Grande do Sul, Brazil. Rev Bras Parasitol Vet. 2016;25(2):172-8.

Guimarães AM, Rocha CMBM, Oliveira TMFS, Rosado IR, Morais LG, Santos RRD. Fatores associados à soropositividade para Babesia, Toxoplasma, Neospora e Leishmania em cães atendidos em nove clínicas veterinárias do município de Lavras, MG. Rev Bras Parasitol Vet. 2009;18(Supl 1):49-53.

Lemos TD, Cerqueira AMF, Toma HK, Silva AV, Corrêa RGB, Paludo GR, et al. Detection and molecular characterization of piroplasms species from naturally infected dogs in southeast Brazil. Rev Bras Parasitol Vet. 2012;21(2):137-42.

Makino H, Sousa VRF, Fujimori M, Rodrigues JY, Dias AFLR, Dutra V, et al. Ehrlichia canis detection in dogs from Várzea Grande: a comparative analysis of blood and bone marrow samples. Cienc Rural. 2016;46(2):310-4.

Manoel CS. Alterações clínicas, hematológicas e sorológicas de cães infectados por Ehrliquia canis [dissertação]. São Paulo: Universidade de São Paulo; 2010. p. 17-25.

Mendonça CS, Mundin AV, Costa AS, Moro TV. Erliquiose canina: alterações hematológicas em cães domésticos naturalmente infectados. Biosci J. 2005;21(1):167-74.

Rivero R, Minoli P, Parodi P, Matto C, Armúa-Fernández MT, Gianneechini E, et al. Descripción de un foco de rangeliosis canina en el litoral noroeste del Uruguay. Veterinaria (Montevideo). 2017;54(208):15-22.

Rotondano TEF, Almeida HKA, Krawczak FS, Santana VL, Vidal IF, Labruna MB, et al. Survey of Ehrlichia canis, Babesia spp. and Hepatozoon spp. in dogs from a semiarid region of Brazil. Rev Bras Parasitol. 2015;24(1):52-8.

Silva AB, Costa AP, Sá JC, Costa FB, Santos ACG, Guerra RMSNC. Detecção molecular de Babesia canis vogeli em cães e em Rhipicephalus sanguineus na mesorregião do oeste maranhense, nordeste brasileiro. Cienc Anim Bras. 2012;13(3):388-95. 
Soares JF. História natural da Rangeliose [tese]. São Paulo: Universidade de São Paulo; 2014. p. 21-5.

Sousa VRF, Almeida ABPF, Barros LA, Sales KG, Justino CHS, Dalcin L, et al. Avaliação clínica e molecular de cães com erliquiose. Cienc Rural. 2010;40(6):1309-13.

Spolidorio MG, Minervino AHH, Valadas SYOB, Soares HS, Neves KAL, Labruna MB, et al. Serosurvey for tick-borne diseases in dogs from the Eastern Amazon, Brazil. Rev Bras Parasitol Vet. 2013;22(2):214-9. 